University of Nebraska - Lincoln

DigitalCommons@University of Nebraska - Lincoln

\title{
Conducting cross-cultural research in teams and the search for the "culture-proof" variable
}

\author{
Patricia Draper \\ University of Nebraska - Lincoln, pdraper1@unl.edu
}

Follow this and additional works at: https://digitalcommons.unl.edu/anthropologyfacpub

Part of the Anthropology Commons

Draper, Patricia, "Conducting cross-cultural research in teams and the search for the "culture-proof" variable" (2007). Anthropology Faculty Publications. 41.

https://digitalcommons.unl.edu/anthropologyfacpub/41

This Article is brought to you for free and open access by the Anthropology, Department of at DigitalCommons@University of Nebraska - Lincoln. It has been accepted for inclusion in Anthropology Faculty Publications by an authorized administrator of DigitalCommons@University of Nebraska - Lincoln. 
Published in Menopause: The Journal of The North American Menopause Society, Vol. 14, No. 4 (2007), pp. 680-687;

doi: 10.1097/gme.0b013e3180986289 Copyright @ $\odot 2007$ by The North American Menopause Society;

published by Wolters Kluwer/Lippincott. Used by permission.

Submitted December 4, 2006; revised and accepted April 25, 2007.

Project AGE: Age, Generation, and Experience was supported by the National Institute on Aging, grant AG 03110.

\title{
Conducting cross-cultural research in teams and the search for the "culture-proof" variable
}

\author{
Patricia Draper
}

Department of Anthropology and Geography, 826 Oldfather Hall, University of Nebraska-Lincoln, Lincoln, NE 68506

email pdraper1@unl.edu

\begin{abstract}
Objective: Cross-cultural research must always deal with the problem that meaning systems and behaviors cannot be readily compared from one culture to the next because the sociocultural context can vary so widely.

Design: The organizers of Project AGE: Age, Generation, and Experience, a multicultural study of aging, recognized this problem and devised instruments for studying age that allowed for cultural variation as well as comparability at higher levels of abstraction. The principal investigators of Project AGE and the individual researchers made every effort to gain an emic understanding (understanding based on categories recognized by the local respondents) of people's attitudes about aging in the several cultures in which we worked. For comparison to take place, we needed to use similar question frames to elicit comparable information across societies of different types.

Results: Many questions put to people about their attitudes toward their own and other persons' aging were readily understood by our respondents. But some topics proved difficult to investigate systematically across cultures.

Conclusions: In hindsight, we could have achieved additional value from our interviews if we had incorporated some independent measures of physical health and capacity. Such data would have added depth to our discussion of within-site and across-site differences on both the independent measures themselves and their possible correlation with attitudinal data
\end{abstract}

Keywords: cross-cultural research, methods, aging, qualitative data, coding

$\mathrm{A}$ 11 researchers who work in the arena of cross-cultural comparison have the same three problems. First, they must collect information about the lives of people in a single culture and make it meaningful to people outside that culture, in terms of the actual physical and social structures within which the described people live. Second, researchers must collect data that can be compared with similar information collected elsewhere on different people living under similar or different physical constraints. Third, cross-cultural researchers must always confront the "etic" nature of their endeavor, remembering they have come to the task of studying and understanding other people's culturally different experience but from their own vantage point. That is, they have their own reasons for conducting the study in the first place. These are related to the problems they are interested in and to the nature of knowledge in their own cultural system. The etics (the researchers' own justifications) are obvious to the interviewers but will not necessarily be relevant to the thinking of interviewees. ${ }^{1}$ I will address these problems in the context of my own experience as a member of Project AGE: Age,
Generation, and Experience, a cross-cultural study of aging in seven communities of five different societies.

Project AGE was designed to study the experience of aging in seven communities in five societies located in four different parts of the world. The Aging Experience: $\mathrm{Di}$ versity and Commonality Across Culture ${ }^{2}$ was published in 1994 and provides in book form an overview of our findings across the sites. The sampling units for the different communities varied for reasons of the very great diversity among the sites. Detailed information can be found in several of the publications published from Project $\mathrm{AGE}^{2-9}$ (see also Appendix I). The focus of our research was on the cultural contributions to well-being in old age. We wanted to understand how variables of culture, social organization, technological complexity, and societal scale influence how people of different ages perceive aging. The sites were deliberately chosen to maximize the spread across a continuum of simple to complex society. The seven sites were communities in the United States (rural and urban); Hong Kong; Africa (hunter-gatherer and pastoralist); and Ireland (rural and urban). I was a 
Table 1. Locations of the seven communities and researchers of Project AGE

\begin{tabular}{lll}
\hline Country & Community & Researcher* \\
\hline United States & Momence, IN (rural) & Christine Fry \\
& Swarthmore, PA (urban) & Jennie Keith \\
Hong Kong & 4 different neighborhoods (urban) & Charlotte Ikels \\
Ireland & Cliffden, County Cork (rural) & Anthony Glascock \\
& Blessington, Dublin area (urban) & Jeannette \\
& Dickerson- Putman \\
Botswana & Ju/'hoansi, western & Patricia Draper \\
& Ngamiland (rural) & \\
& Herero, western & Henry Harpending \\
& Ngamiland (rural) & \\
\hline
\end{tabular}

* The principal investigators of Project AGE were Christine Fry and Jennie Keith. Project AGE researchers were recruited because of their prior experience in cultures where they had local knowledge and language fluency. The only member of our team of seven investigators who had no prior research experience in her community was Jeannette Dickerson-Putman. However, as a native English speaker, she did not need to work through a translator in Ireland. The first field teams worked in the two US communities and in Hong Kong in the early 1980s. The second set of researchers was in the field from approximately 1987 to 1989 .

researcher at one of two African societies, the Ju/'hoansi of western Botswana. I worked in several villages of the !Angwa and XaiXai Valleys in Ngamiland, western Botswana. My sampling procedure was based on a deliberate oversampling of elders in the region. I was able to include about $75 \%$ of the able-bodied people over the age of 60 years. None of the elders declined to be interviewed, although six were sufficiently frail at the time of my fieldwork that their relatives discouraged me from interviewing them. A few other older people, though technically living in the area, had relocated to Namibia and did not return to my research community on a regular basis. I recruited younger adults on the basis of an opportunity sample, choosing them from the villages in which the elders were living, and made an effort to recruit approximately equal numbers of men and women of different ages from the different villages. Many years ago I began research among these people as a PhD candidate and have returned there on several occasions for further fieldwork. The seven communities of Project AGE and their individual researchers are shown in Table 1.

\section{METHODS}

Culture and its various subcomponents were our independent variables. The dependent variables were people's perceptions of aging and the life course and their self-assessed ratings of their well-being and health status. The independent variables were of two types; 1) sociocultural factors, such as size, density, complexity, technological development, and political organization, and 2) individuallevel variables, such as age, sex, socioeconomic status, occupation, education, and marital status. Our respondents were of all adult ages, from young adult to very old. We interviewed between 105 and 200 people from each site after a lengthy interview protocol designed to recover nor- mative views of aging that were held by people of different ages. We also wanted to document each person's attitudes about their unique experience and expectations as a person of a given age. An important goal was to capture variation in people's evaluations of aging as it reflected their own age at the time of interview.

We devised a series of questions that we thought were approximately equivalent, reasonably unambiguous, and able to address the same underlying issues. I provide below a sample of our questions, which we hoped would yield both normative and egocentric answers. In developing these questions, we recognized that what a respondent might have in mind in answering a question would not necessarily match exactly the shades of meaning we had in mind when we formulated the question.

- What words do you use to refer to people of different ages? (record the number and names of age terms used by each respondent)

- What kinds of things happen to move a person from the first stage to the next and successive stages?

- How are these people (to whom you have given different age labels) different from each other?

- What is good about being at that age? (for each age stage named)

- What is bad about being at that age? (for each age stage named)

- Think of an old person who is doing well/badly. What is it that makes life good/bad for that old person?

- How would you rate the quality of your own life on a scale of 1 to 5 ?

- How would you rate your own health on a scale of 1 to 5? (additional questions about separate components of health, such as vision, hearing, skeletal function, digestion, etc.)

- If you could change your age, what age would you most/least like to be?

\section{Internal explanation}

Data, of course, never speak for themselves. Once we had answers to questions about the dependent variables, we had to interpret them in such a way that our audience, primarily educated Westerners, would be interested and stimulated to think more concretely about how culturally embedded the experience of aging might be. We took the answers to our questions, site specifically, and explained how they made sense given the kinds of lives people were leading. Tony Glascock, writing about his sample of rural Irish, reported that many of his elderly respondents rated themselves high on well-being despite experiencing living conditions at the time of interviews that would seem harsh to most Western urbanites. He explained that these high ratings stemmed from the fact that his interviewees could remember how badly off old people had been in former times, in contrast to their own relative comfort in the present as recipients of many government-provided services to old people. In contrast, many elderly Ju/'hoansi, the people at my research site, 
rated themselves very low on well-being. I explained this reversal by pointing out that old people living in remote, rural Botswana, with only rudimentary technology, had no cushion against the infirmities of old age. Ju/'hoansi spent most of their waking hours out-of-doors. Most people had no furniture; every excursion involved walking or, more rarely, riding a donkey. Even the routine act of sitting down required a person to assume a full squat to the ground. Jennie Keith, whose US community was the affluent suburb of Swarthmore, PA (outside Philadelphia), could provide a rationale for the fact that a high percentage of her elderly informants said their health was "good" or "excellent" because their affluent lifestyle, good access to medical care, and labor-saving devices muted the impact of their own failing capacities. ${ }^{7,8}$

In each of these cases the researchers took at face value what the respondents said about their well-being or health. We then inferred the logical basis of the answers. We could provide a rationale for the fact of different selfratings by people living in different conditions because each of us had done ethnographic background work to prepare for interviewing and had acquainted ourselves with the basic sociocultural context of our participants. In fact, most of us had research experience in these locations before our recruitment into Project AGE. We spoke the field languages, and we could interpret the meaning of the frequently occurring answers we collected within each site against the backdrop of this knowledge.

However, our interpretive portraits did not rely on having access to independently verifiable measures on each respondent, which would have made it possible to compare how a respondent rated his own well-being on some measure against some objective measure of that respondent's unique condition in terms, for example, of physical functionality or of some social measure, such as availability of kindred.

An example may help make the problem more concrete. It is theoretically possible to have independently measured some component of bodily health or physical functioning, such as visual acuity (using a relatively simple tool suitable for use by nonspecialists in different field settings). Knowing how a given person performed on the independent test of vision could be compared with the same person's self-assessed vision scores. Similarly, a person's overall scores based on the several independent measures of physical capacity could be correlated with the person's self-scoring on well-being or morale.

A cautionary note is in order. Merely knowing that a given person might prove to be visually impaired to some degree (on the basis of the independent measure) relative to another person in that same society does not necessarily predict how a person may evaluate or express his well-being. Among the Ju/'hoansi elders, many no longer had the good close-distance vision necessary for reading and writing, a skill essential to people of all ages in developed societies. However, poor close vision was not a major handicap for old Ju/'hoansi. All of them were illiterate, and few owned any written documents. Should we conclude that an independent assessment of vision would have been unnecessary for older Ju/'hoansi? On the contrary, and particularly in the context of interpreting crosscultural data, having the independent measure makes it possible to investigate the relativity of the experience of aging and the importance of understanding the fine grain of cultural differences. The value of the independent measure is that it "stands alone" for what it is, a valid and allegedly objective measure of some phenomenon that can be reliably used on different people in the same and in different settings. The discovery, if and when it comes, that one or more independent measures predict differently for respondents' attitudes or self-ratings can be extremely useful and often the trigger for later, serendipitous understandings by the researchers.

Though we lacked independent measures of physical functioning, we went partway toward creating a measure that was capable of both within-culture constancy and cross-cultural comparability. We used the "self-anchoring" measure of self-assessed ratings of well-being and asked people to rate themselves high or low on a five-point scale. Nevertheless, even when respondents provided self-ratings, there was no way of knowing how those scales were anchored by each interviewee, and it was doubtful that the informants assigned scrupulously equal intervals to the distance between the five points. Despite these difficulties we found telling differences among respondents between and within societies on the basis of the self-anchoring rating scale. ${ }^{2,9}$

\section{Comparative explanation}

Cross-cultural research must always deal with the problem of meaningful comparison. Meaning systems and behaviors cannot be readily compared from one culture to the next because the sociocultural context can vary so widely.

For example, elders in the United States are likely to stress their ability to perform routine activities of daily living because they derive self-esteem and believe they gain respect from others by remaining self-sufficient and independent. In addition, and as a practical matter, most elders do not have younger relatives in the household to perform services for them. In comparison, many elderly household members living in extended-family households in traditional societies have two advantages over their Western peers: they have assistants close at hand and, as elders, they feel entitled to ask for and to receive help from younger people. ${ }^{10,11}$ In sub-Saharan Africa, children are frequently fostered to elderly kin specifically to provide them with company and domestic help. ${ }^{12-14}$

Our research team devised instruments for studying age that allowed for cultural variation as well as comparability at higher levels of abstraction. We met as a team on several post-fieldwork occasions to discuss the answers to specific questions and groups of questions from across sites. It was evident that certain themes were recurrent, though phrased in somewhat different ways. We agreed to re-conceptualize the answers as falling into one 
of four categories: physical health and capacity, material wealth and resources, family and kinship, and personal issues of outlook, philosophy, or ideology. The common denominators that we recognized were meaningful to us; however, individual coding decisions could not always be justified on a strict or literal translation from the original vernacular in which they were expressed.

The phase of cross-cultural work in which coding judgments are made is where distortions of meaning can enter. In the process of collapsing "raw" answers into higher level categories, a number of things can be lost. This criticism could be levied at any cross-cultural exercise in which data are based on respondent opinion and attitude. Researchers must let respondents speak their minds in terms meaningful to themselves. Yet if there is no higher order of abstraction, the "coding" of differently phrased sentiments into a more general category, the possibility of comparison is limited.

Here is an example of coding problems from my own research site. I mentioned previously that in some of our analyses we were working with a fourfold coding scheme that distinguished among physical functional capacity, material wealth and resources, family and kinship, and personal issues of outlook and worldview. When I inspected the Ju/'hoan answers to various questions about the meaning of aging for their own or other people's health and well-being, I could not readily distinguish between their answers that mentioned bodily strength and health and their answers that mentioned material well-being and material resources or "wealth." On the basis of my knowledge of their lives, I realized that although our distinct coding categories (bodily functioning vs. wealth or property) were conceptually meaningful to us as researchers, these concepts were not separated in the same way in Ju/'hoan minds. Ju/'hoansi were technologically the most simple among the Project AGE participants. People owned very little property and had only sporadic access to money from the sale of traditional handicrafts. Theirs was not a pristine subsistence economy in which all foods and material items were produced by individual effort, although they were more impoverished in a material sense than people of any of the other cultural sites. ${ }^{15}$

In thinking about this blending of concepts related to physical, bodily functioning and material well-being, I concluded that for the Ju/'hoansi their bodies were the same thing as their tools and wealth. In their answers they were saying, when the body fails, the way of getting food and getting work done also fails. Because they lived in small villages composed of long-term kindred and relatives by marriage, older people could still subsist and have lives worth living. Their solution was to replace their own failing capacity with the bodies of other people, especially younger bodies who were close family members.

After much discussion we Project AGE researchers devised a means of coding the Ju/'hoan answers that contained comments combining physical functioning and livelihood, but at the expense of an important emic, meaning at the expense of an important component of the meaning of work as understood by Ju/'hoansi.

Another type of confound will be familiar to crosscultural researchers. Answers given in private to an interviewer who the speaker believes will protect anonymity can often be different from answers by the same respondent when they are given in a semipublic setting. In such cases it could be important to standardize interviews across sites for a "one-on-one" format, though such a decision could make it difficult to recruit interviewees. In some societies where much of life goes on in semipublic settings, being seen in private or closed-door conversation with a relative stranger can arouse unfavorable comment. If standardization of the interview setting is not possible across sites, a rule could be imposed on each researcher to code for the private versus public context in which each interview was conducted. With such information available, and that is independent of informant report, the researchers could sort answers both within and between sites on the basis of whether other parties were privy to the interview.

Another example of a cross-cultural confound comes in the form of rules about answering certain questions, which can overwhelm the possibility of uncovering individual difference. Project AGE researcher Charlotte Ikels reported that the Chinese of Hong Kong were largely unwilling to rate themselves as either very positive or very negative because they didn't want to "stand out." Among the Ju/'hoansi the cultural rules are quite different. According to the normative "complaint discourse" among $\mathrm{Ju} /$ 'hoansi, it is expected that people, especially elders, will exaggerate and proclaim loudly and publicly their neediness as a way of winning assistance from others. ${ }^{16}$ In stark contrast, many North American elders will deny or de-emphasize their physical or emotional needs because they don't want to be a burden on their younger kin. Factors such as these make it difficult to develop a valid description of cultural behavior while at the same time staying close to the data. The knowledgeable researcher can include a description of such a confound by reporting, as in the case of Chinese self-ratings, a strong central tendency in the frequencies of response.

What way is there out of these interlocking complexities? Part of the answer is to include data in the stream of inference that are, relatively speaking, "culture-proof" as well as theoretically relevant to the problem orientation of the investigators. By culture-proof I mean that there are facts of life and experience that arguably influence the quality of life for all human beings. If systematic, objective, and empirical measures on such "facts" are collected across all the research sites, a separate body of information accumulates and can be separately analyzed for its association with various types of response data. For example: (1) such data can be meaningful as stand-alone assessments; (2) such data can be juxtaposed against the same respondent's answers to open-ended questions; (3) data of this type can be analyzed in concert with other independent variables at the cultural or indi- 
vidual level; and (4) these data can be compared from one site to another.

My sense now is that Project AGE would have been strengthened if more independent variables had been identified that were specified at a level extremely close or proximate to the individual and that had theoretical relevance to well-being at older ages regardless of cultural setting. Such information would have given us a different kind of leverage on factors in the lives of our participants that were contributing to the answers we received. Another reason for making this proposal to gather objective, systematic data "close up" on each respondent across the five societies is that the scale differences among our communities were so great that it was hard to remain mindful of the heterogeneity among our individual participants. Our mostly sociodemographic independent variables lost analytic specificity when used across sites.

As mentioned previously, Project AGE researchers recorded numerous independent variables pertaining to individuals, such as age, gender, socioeconomic status, level of education, occupation, and marital status. Readers may be thinking that such information is, in fact, quite close to the individual. However, at several of our research sites, particularly among the recently hunting and gathering $\mathrm{Ju} /$ 'hoansi and to a lesser extent among the pastoral Herero, many people did not know their own absolute ages, had never been to school, did not participate in a wage economy, did not have what we would call a "formal occupation," and had no readily assessed socioeconomic status. A similar problem applied to some of the older rural Irish. In this sense, some of the individual-level, independent variables that Project AGE specified were not culture-proof.

\section{Individual-level variables}

What kind of individual-level variables could have been added? How would they have been collected, given that the Project AGE researchers were mostly cultural anthropologists without a common base of technical skill in some allied medical or biological science? Following are a few suggestions, based on my own preference and research interests. Others could be identified for different researchers working with different research problems. I will give a simple accounting of them and then explain why having such information could have improved the quality of inferences we drew from the interviews. All readers will recognize that resources to support cross-cultural research are limited. Any modification that I propose, retrospectively, would have added costs and time that might have negatively impacted our funding, our ability to find field workers, or our ability to win research permission from host countries.

What follows is list of culture-proof variables that could have been included without major distortions to the feasibility of our goals. Because we were concerned with cultural variation in well-being among people of different ages, we could have made excellent use of independent measures of physical capacity, such as field tests of hand-grip strength, balance, ability to execute simple maneuvers that test joint flexibility, and other measures of vital capacity. Grip strength has been assessed in many populations using a hand dynamometer, a tool that is applicable to different field settings. Research has shown that grip strength tracks disabilities that are not obvious to a casual observer. Furthermore, grip strength has been shown to predict disability and mortality risk as much as 20 years into the future. ${ }^{17}$ In a recent study of New York and Delhi elders, the Indian sample showed markedly weaker grip across categories of disease profile, gender, and age. ${ }^{18}$ The interpretation of such findings is often impossible without further study. Causes or precursors of population differences in hand weakness could be physiological, having to do with senescent failures. Contributors could be behavioral, the result of relative inactivity in the lifestyle of older urban Indians. The advantage of data on grip strength is that the measurements can be reliably and quickly collected. The variable has good external validity. Variation among participants of the same or different ages is readily apparent and can lead to followup questions by researchers while they are still in the field.

Similarly, obtaining data on height, weight, and other measures of physical capacity has the advantage of readily available comparison data from numerous previous studies. Measurements of body mass index and central obesity (waist circumference) have proved valuable in studies with longitudinal tracking of participants. It is known that obesity and particularly abdominal fat are risk factors in Western populations. ${ }^{19}$ Levels of male and female hormones decline with age and carry associations with obesity. A reduced level of testosterone, in particular, is a risk factor for cognitive impairment. ${ }^{20}$ Recent technical developments have made it possible to collect and preserve saliva samples for hormonal analysis under a variety of challenging field conditions. From their work on anthropological populations, Ellison and colleagues ${ }^{21}$ have reported very substantial mean differences in testosterone among males of four geographically distinct populations (United States, Congo, Nepal, and Paraguay). The male hormone levels of the US population were more than twice the level of a Paraguayan Indian population and remained elevated in US participants across age groups, raising questions for Western clinicians about testosterone-dependent factors of bone density and prostate cancer and the possible deleterious effects of prolonged exposure to high levels of male hormone. ${ }^{21}$

In each of these examples, only briefly considered, there are independent measures of physical capacity that can be collected quickly and relatively cheaply in the field. Clinical studies already done in Western populations indicate the health implications associated with these measures. The research participants are usually recruited from societies in which the effects of Western dietary practices are pervasive and where the demands of physical activity are reduced. ${ }^{22,23}$ As a result the health implications for even non-Western groups converge on the findings for Western societies. Therefore, it can be ex- 
tremely beneficial for workers in the biomedical field to combine forces with social science researchers working in areas with relatively little outside influence. Extremely productive work can result from this kind of synergism.

Drawing on another illustration from my own research site in Botswana, the Ju/'hoansi have been documented as exhibiting extreme thinness during and before the time of my fieldwork. ${ }^{24-26}$ The low weight of adults and children was somewhat ameliorated 20 years later at the time of the research reported for this paper, when my research participants were no longer living by mobile foraging. On the other hand, their nutritional status was not good, as evidenced by the unfortunately high rates of tuberculosis infection by which they had recently become victimized.

The culturally different Herero, who were their close neighbors, had very superior diets higher in fat and protein, supplied through regular consumption of milk from their cattle herds. ${ }^{15}$ Few Herero suffered from tuberculosis despite living in the same environment, in some cases the same villages, and having frequent social contact with Ju/'hoansi. I suggest that knowledge of such physical indicators as height and weight of individuals would have given us substantial leverage in interpreting within- and across-site differences, not only for the African populations but also for the urban and modernized groups who were studied for Project AGE. It is possible that relative thinness, an indicator of undernourishment, may have explained some of the variation among the Ju/'hoansi, many (but not all) of whom rated their well-being negatively. Herero, as explained above, had greater material wealth and, not coincidentally, were taller and heavier than Ju/'hoansi. Continuing with conjecture, it is possible that a height/weight measure may have borne no relationship to self-assessed well-being among the Herero, whereas it may have been positively related to self-assessed well-being among Ju/'hoansi. Such a finding, in and of itself, would be illuminating and could have provided another way of understanding the experience of aging in the two cultures that did not depend on self-report.

A final example of an individual-level variable that may pass the test of being culture-proof is that of an egocentric kinship inventory. It is a truism among age researchers who work in developed societies: with advancing age, family connections with siblings, children, and grandchildren become more important as the individual invests less in work roles and other kinds of voluntary activity. ${ }^{27-29}$ It is equally well understood among researchers who work with traditional societies (as well as by the members of the societies that we study) that connections of kinship and marriage provide the basis of major portions of economic and social activity. ${ }^{30}$ Therefore, it is easy to argue that researchers should know the sociometric and genealogical details of each person's kinship universe. Such data stand the test of "culture-proof-ness" since almost everyone knows the details of their own births and has connections with genealogical ascendants, descendants, and collateral kin. People's knowledge of the marital and reproductive histories of their close kin is often equally detailed. The same can be said for adoptees, though the kin connections would be described as "fictive" but would have comparable emotional and practical significance. The import of being kin rich or kin poor in all likelihood will vary from site to site and even within sites for people of different ages. Yet knowledge of such "facts" could be gained in a straightforward manner, and respondents could be compared among themselves with regard to these data points. The practical or subjective meaning of having many or few kin is undoubtedly culturally variable, yet the facts in terms of presence, or absence, or sheer counts of different kinds of kin can stand alone and thereby constitute a solid basis of comparison within and among sites,

Speaking as a researcher who has done this kind of interviewing, I believe it is important to warn that such interviewing can be time consuming, particularly if the respondent is asked to provide additional details on each named person, such as whether alive or dead, residence location, frequency of contact, etc. Nevertheless discrete egocentric data on kin networks have great potential for creating inferential bridges to other kinds of information already collected within sites. Gerontologically inclined researchers have been highly productive in this type of research, linking kin network data to both demographic and self-assessed variables of health and well-being. ${ }^{29,31-34}$

The cross-cultural team research that I participated in produced detailed findings on an extremely broad range of societies. The research design we followed provided an opportunity to separately examine the effects of culture and age on people's perception of the aging process. An exceptional strength of the book Age, Generation and Experience was the rich ethnographic background that the authors provided as an accompaniment to the quantitative findings from the cross-site interviews. ${ }^{2}$ My comments on the lack of what I have called culture-proof variables are not meant to detract from the impressive accomplishments of the AGE Project research team. In actuality, of course, there are no truly culture-proof variables, if by that term we mean a set of measures that can be collected anywhere on any person that will yield the same insights into a research problem. For example, clinicians who follow the cross-cultural literature on hypertension are especially sensitive to the complex relationships that measures of hypertension have with a large suite of independent variables, such as modernization, occupation, race, and ethnicity, as well as age and age-dependent hormonal profiles. ${ }^{35-37}$

\section{CONCLUSIONS}

In conclusion, I have made a general recommendation to cross-cultural researchers who work principally with attitudinal data that they include among their inventory of independent variables a series of measures that are extremely close to the sensory and quotidian aspects of life of their informants. The "closer to the skin" the better, be- 
cause the more proximate the feature is to the individual, the greater the probability the same component will register meaningfully in the consciousness of people everywhere. Examples have been given in the form of physical measures such as grip strength, height, weight, waist circumference, and saliva specimens for hormonal analysis; a social measure has been suggested in the form of an inventory of relatives (both by blood and by marriage).

Certain advantages will result from operationalizing a battery of so-called culture-proof variables. First, there will be an inventory of independently acquired data against which an informant report can be contrasted, and this will free researchers from taking the informant report at face value. Second, the data from the culture-proof variables can be considered as standing alone for the purposes of contrasting individuals within sites as well as between sites. Last, and most important, is the reminder that data never speak for themselves. No matter what methodology is adopted, and regardless of the precision of instruments, reliability of data collection, and rigor of analysis, all findings require interpretation, which itself rests on the insight and sensitivity of the writer.

\section{REFERENCES}

1. Harris M. History and significance of the emic/etic distinction. Annu Rev Anthropol 1976;5:329-350.

2. Keith T, Fry CL, Glascock AP, et al. The Aging Experience: Diversity and Commonality Across Cultures. Thousand Oaks, CA: Sage Publications, 1994.

3. Fry C. Globalization and the experiences of aging. Gerontol Geriatr Educ 2005;26:9-22.

4. Fry C. Kinship and supportive environments of aging. Annu Rev Gerontol Geriatr 2003;23:313-333.

5. Ikels C. Delayed reciprocity and the support networks of the childless elderly. J Comp Fam Stud 1988;19:99-112.

6. Ikels C. Becoming a human being in theory and practice: Chinese views of human development. In: Kertzer DI, Schaie KW, eds. Age Structuring in Comparative Perspective. Hillsdale, NJ: Lawrence Erlbaum Associates. 1989:109-134.

7. Keith J. Age in social and cultural context: Anthropological perspectives. In: Binstock RH, George LK, eds. Handbook of Aging and the Social Sciences, 3rd ed. New York, NY: Academic Press, 1990: 91-111.

8. Keith J, Fry C, Ikels C. Community as context for successful aging. In: Sokolovsky J, ed. The Cultural Context of Aging: Worldwide Perspectives. New York, NY: Bergin \& Garvey, 1990:245-261.

9. Fry C. Culture, age and subjective well-being: Health, functionality and the infrastructure of eldercare in a comparative perspective. J Fam Issues 2000;21:751-776.

10. Lindsey E, Hirschfield M, Tlou S. Home-based care in Botswana: Experiences of older women and young girls. Health Care Women Int 2003;24:486-501.

11. Zimmer Z, Dayton T. Older adults in sub-Saharan Africa living with children and grandchildren. Popul Stud 2005;59:295-312.

12. Isiugo-Abanihe UC. Parenthood in sub-Saharan Africa: Child fostering and its relationships with fertility. In: Locoh T, Hertrich V, eds. The Onset of Fertility Transition in
Sub-Saharan Africa. Liege, Belgium: International Union for the Scientific Study of Population, 1994: 163-174.

13. Bledsoe C. Marginal members: Children of previous unions in Mende households in Sierra Leone. In: Greenhalgh S, ed. Situating Fertility: Anthropology and Demographic Inquiry. Cambridge, UK: Cambridge University Press, 1995:130-153.

14. Bledsoe $\mathrm{CH}$. The politics of children: Fosterage and the social management of fertility among the Mende of Sierra Leone. In: Handwerker WP, ed. Births and Power: Social Change and the Politics of Reproduction. Boulder, CO: Westview Press, 1990:81-100.

15. Draper P, Harpending H. Cultural considerations in the experience of aging: Two African cultures. In: Bonder BR, ed. Functional Performance in Older Adults. Philadelphia, PA: F. A. Oavis, 1994:15-27.

16. Rosenberg HG. Complaint discourse, aging and caregiving among the !Kung San of Botswana. In: Sokolovsky I, ed. The Cultural Context of Aging: Worldwide Perspectives, 2nd. New York, NY: Bergin \& Garvey, 1997.

17. Rantanen T, Guralnik JM, Foley D, et al. Midlife hand grip strength as a predictor of old age disability. JAMA 1999;281:558-560.

18. Albert SM, Alam M, Nizamuddin M. Comparative study of functional limitation and disability in old age: Delhi and New York City. J Cross Cult Gerontol 2005;20:231-241.

19. Derby CA, Zilber S, Brambilla D, Morales KH, McKinlay JB. Body mass index, waist circumference and waist to hip ratio and change in sex steroid hormones: The Massachusetts Male Ageing Study. Clin Endocrinol 2006;65:125-131.

20. Barrett-Connor E, Goodman-Gruen D, Patay B. Endogenous sex hormones and cognitive function in older men. $J$ Clin Endocrinol Metab 1999;84:3681-3685.

21. Ellison PT, Bribiescas RG, Bentley GR, et al. Population variation in age-related decline in male salivary testosterone. Hum Reprod 2002;17:3251-3253.

22. Dressler WW, Bindon JR. The health consequences of cultural consonance. Am Anthropol 2000;102:244-260.

23. Murphy HBM. Blood pressure and culture: The contribution of cross-cultural comparisons to psychosomatics. Psychother Psychosom 1982; 38:244-255.

24. Draper P, Howell N. Changes in co-survivorship of adult children and parents: Ju/'hoansi (!Kung) of Botswana in 1968 and 19118. Senri Ethnol Stud 2006;70:81-100.

25. Draper P, Howell N. The growth and kinship resources of !Kung children. In: Hewlett B, Lamb M, eds. HunterGatherer Children. New Brunswick, NJ: Transaction, 2005:262-281.

26. Lee RB. The !Kung San: Men, Women and Work. Cambridge, UK: Cambridge University Press, 1979.

27. Antonucci T, Akiyama H. Social networks in adult life and a preliminary examination of the convoy model. J Gerontol 1987;42: 519-527.

28. Rosenthal CJ. Family relationships and support in later life. J Can Stud 1993;28:122-138.

29. Wenger GC. Social networks and gerontology. Rev Clin Gerontol 1996;6:285-293.

30. Berkman L. The role of social relations in health promotion. Psychosom Med 1995;57:245-254.

31. Antonucci TC. Social relations: An examination of social networks, social support, and sense of control. In: Birren JE, ed. Handbook of the Psychology of Aging, 5th. San Diego, 
CA: Academic Press, 2001: 427-453.

32. Bott E. Family and Social Network: Roles, Norms and External Relationships in Ordinary Urban Families. New York, NY: Free Press, 1971.

33. Kahn RL, Antonucci TC. Convoys over the life course: Attachment, roles, and social support. In: Baltes PB, Brim OC, eds. Life-span, Development, and Behavior. New York, NY: Academic Press, 1980:254-283.

34. Wenger GC. Understanding Support Networks and Community Care: Network Assessment for Elderly People. Aldershot, UK: Avebury, 1994.
35. Brown DE. Job strain and physiological stress responses in nurses and nurse's aides: Predictors of daily blood pressure variability. Blood Pressure Monit 2003;8:237-242.

36. James GD, Brown DE. The biological stress response and lifestyle: Catecholamines and blood pressure. Annu Rev Anthropol 1997;26: 313-335.

37. Dressler WW. Culture and the risk of disease. Br Med Bull 2004;69: 21-31.

\section{APPENDIX I}

\section{Site-specific sampling procedures}

Descriptions of site-specific sampling procedures can be found in References 2 through 8 . The researchers in the three complex and modernized settings (United States, Hong Kong, and the Dublin area of Ireland; Fry, Keith, Ikels, and Dickerson-Putman; see Table 1) followed randomized procedures for choosing participants, utilizing census blocks (and selective mailings) based on neighborhood boundaries. The other three researchers (Glascock, Harpending, and Draper; Table 1) worked in less modern and less densely populated settings in rural Ireland and in remote rural areas of Botswana occupied by members of the Herero and Ju/'hoansi groups. The researchers of the small-scale societies followed more informal rules of developing a study sample. All three of these researchers reported very few refusals to be interviewed, a fact made more understandable by the small size of the communities and the decision of the researchers to spend the first months of the research making frequent visits to individuals and community centers, where they collected basic information about the communities by means of preliminary and informal interviews. For all five societies the goal was to recruit 200 interviewees, of whom a larger proportion was to be older than 60 years of age. All researchers succeeded in obtaining an oversample of elderly interviewees. The researchers working in the complex society sites succeeded in reaching the desired goal of 200 interviewees. The researchers working in the more traditional societies, including the rural Irish, were able to interview smaller numbers, 105 for $\mathrm{Ju} /$ 'hoansi and approximately 150 for the rural Irish and Herero. The smaller number of recruits in the more traditional communities was not due to lack of cooperation but rather to the longer amount of time it took to gather information. In the case of the two of us who worked in rural Africa (Harpending and Draper), it took longer to find our participants, once they had agreed to be interviewed, because of the frequent visiting and occasional temporary moves out of the area. The Botswana respondents lived in different communities, separated by many miles, in remote areas not served by paved roads, electricity, or telephone communications. These factors affected our ability to follow up on participants for whom only partial information was gained in the initial round of interviewing. In Botswana the interviews themselves proceeded more slowly, sometimes requiring return visits. None of the Ju/'hoan interviewees had experienced formal schooling, and they were unaccustomed to thinking about aging in the way our interview protocol required. The same kinds of difficulties were encountered to some extent by Harpending, who interviewed the Herero, though his respondents were more forthcoming as interviewees, in part because some were literate (although not in English) and because their own society recognized status and stratification differences based on wealth in cattle and the chronological age of the individual. The Herero, therefore, found it easier to think about the norms and roles appropriate to persons of different ages than did the Ju/'hoansi. The latter have traditionally lived in small, mobile, kin-based bands, pursuing an economy in which adults of all ages carried out the same kind of work roles. Ju/'hoansi, in comparison with Herero, were not accustomed to status and wealth differentiations among people of their own kind. They found it unfamiliar and somewhat mystifying to contemplate the social norms associated with people of different absolute ages. Instead they made distinctions among themselves based on personal history, kinship, and marital ties. 